ENCARTE DIGITAL 2 i VARIA

\title{
Utopia em Jonas e Levinas
}

Utopia in Jonas and Levinas

* Ozanan Vicente Carrara

\begin{abstract}
Resumo: Jonas e Levinas são dois nomes intimamente associados à ética contemporânea. Embora não sejam nomes ligados, de maneira inequívoca, ao pensamento utópico, contribuem, no entanto, de maneira decisiva, para repensar a utopia. Proponho-me buscar nos dois autores e em seus textos os elementos de sua leitura crítica que permitem analisar e repensar a questão da utopia tal como ela se encontra formulada pelos pensadores a ela mais diretamente associados como Bloch, Buber e Bacon.
\end{abstract}

Palavras-chave: Ação ética. Alteridade. Ciência. Socialismo. Utopia.

\begin{abstract}
Jonas and Levinas are two names intimately associated with contemporary ethics. While they are not unequivocally linked to utopian thought, they have nonetheless decisively contributed to rethinking utopia. In this essay, I seek in these two authors and their texts the elements of a critical reading that would allow us to analyse and reconsider the question of utopia as it is formulated by thinkers more directly associated with it, such as Bloch, Buber and Bacon.
\end{abstract}

Keywords: Ethical Action. Otherness. Science. Socialism. Utopia.

\section{A Utopia em Hans Jonas}

o propor uma ética do futuro, Jonas se ocupa também de uma política
dois sistemas políticos ou os dois modos de governar da nossa época,
quais sejam o socialismo ancorado na ideologia marxista, na versão de
Ernest Bloch, e o do liberalismo, em sua versão capitalista. Apesar de

* Doutor em Filosofia pela UERJ. Professor adjunto II da Universidade Federal Fluminense. <ozanan.vc@uol.com.br>. 
apontar os dois referidos modelos como referenciais em sua análise, ele não se detém longamente numa análise do capitalismo, limitando-se a considerá-lo inadequado para enfrentar os problemas trazidos pelas questões ambientais e pelos perigos da civilização tecnológica.

Em suas análises do marxismo, Jonas o vê como o fiel herdeiro de Francis Bacon em seu projeto moderno de dominação da natureza e de transformação tecnológica da sociedade. A ciência e a tecnologia, na visão de Bacon, preparariam o advento do novo homem. Jonas analisa o marxismo na versão utópica de Ernest Bloch que entende que o homem verdadeiro ainda está por vir. A história foi até agora apenas uma preparação para esse homem do futuro. Além da utopia baconiana de um homem com poder crescente sobre a natureza, a utopia marxista lhe acrescenta a sociedade sem classes, contendo ela assim uma ética do futuro. O marxismo, diz Jonas, almeja a realização do ideal baconiano uma vez que conteria a receita que geraria um gênero humano superior. Há então no marxismo uma escatologia ativa, embora o socialismo tenha nascido de um modo tecnicista de relação ao mundo. A aceleração da industrialização foi sempre uma marca dos governos socialistas já que ela garantiria uma maior socialização das riquezas. Para Jonas, "a lógica que comanda o projeto socialista consiste em igualar e depois ultrapassar o capitalismo na coleta dos frutos obtidos graças à técnica"1. Estaria então o socialismo em condições mais vantajosos para melhor enfrentar os perigos da civilização tecnológica e para impedir uma catástrofe humanitária do que o capitalismo? A sociedade sem classes, fim último da utopia marxista, seria realmente capaz de preservar a humanidade dos perigos que a ameaçam?

Ele admite que o Socialismo possua algumas vantagens sobre o capitalismo que o tornariam mais apto a enfrentar os riscos da civilização tecnológica e isso se deve a algumas razões como as seguintes: 1) Maior racionalização por parte deste na gestão dos recursos e das necessidades devido ao seu planejamento centralizado que funcionaria como um freio na exploração ilimitada dos recursos naturais do planeta enquanto o capitalismo se guia basicamente pelo desejo de lucro; 2) Um governo socialista estaria em melhores condições de impor escolhas impopulares à maioria do que um governo que precisa atender às exigências dos seus cidadãos para se manter no poder como é o caso de governos democráticos e liberais que, aliás, são governos de curto termo; 3) A ideia de viver para a sociedade e de se sacrificar por ela, exigências trazidas

1 JONAS, Hans. O Princípio Responsabilidade. Ensaio de uma ética para a civilização tecnológica. Trad. Marijane Lisboa; Luiz Barros Montes. Rio de Janeiro: Contraponto/Editora PUC-Rio, 2006, p. 241. 
pelas questões ambientais, é mais aceitável dentro da cultura socialista; 4) O socialismo poderia melhor motivar seus membros à privação já que a cultura capitalista promete o hedonismo sem limites. A utopia marxista promete uma felicidade futura pela qual se devem sacrificar escolhas e opções no presente; 5) O marxismo exige o sacrifício de todos e não somente dos mais pobres em benefício de uma maior qualidade de vida para os mais bem situados social e economicamente, como é a tendência no sistema capitalista, embora ele admita que a sociedade sem classes não está desprovida da hierarquização social².

No entanto, essa superioridade do socialismo em relação ao capitalismo é apenas aparente. Revendo as supostas vantagens do socialismo sobre o capitalismo, Jonas admite que a ideia da maximização está tão presente no socialismo quanto no capitalismo e que há apenas uma curta distância entre a ideia de maximização e a ideia de lucro. Além disso, Jonas fala de um culto da técnica que goza de grande prestígio no socialismo, pois o fim deste é liberar a técnica de todos os entraves que impedem a realização plena do ser humano ${ }^{3}$.

O socialismo não pensa que seja possível um limite natural à ação humana, mas alimenta a pretensão ilimitada da ciência e da técnica, tornando-se a natureza, nesse modelo, um mero meio para a autoprodução do homem ainda inacabado4. Quanto à utopia marxista, seu fim é o estado justo que seja capaz de abolir as distinções de classe, estabelecendo a justiça e a equidade. Somente num estado assim, o verdadeiro potencial humano poderia ser liberado. Na concepção marxista, o homem é essencialmente bom, mas as circunstâncias o distanciam dessa bondade, tornando-o mau ${ }^{5}$. Faz-se necessário então agir sobre as circunstâncias através da revolução que conduzirá à sociedade sem classes. Atingido esse objetivo, o homem se revelará em sua natureza essencialmente boa.

Jonas parte da constatação de que houve grande progresso nas ciências naturais, mas o progresso moral não acompanhou o progresso intelectual. $\mathrm{O}$ homem avançou no conhecimento sobre a natureza, mas deixou em segundo plano o conhecimento sobre si mesmo, sobre a sociedade e a história. E a justificativa que ele encontra para tal constatação é que "aqueles assuntos não são passíveis de ser conhecidos no mesmo sentido em que o são os fenômenos naturais" ${ }^{6}$. Mas pode-se

\footnotetext{
2 SCHOEFS, Virginie. Hans Jonas: écologie et démocratie. Paris: l'Harmattan, 2009, p. 53-57.

3 JONAS, Hans. O Princípio Responsabilidade. Ensaio de uma ética para a civilização tecnológica. Trad. Marijane Lisboa; Luiz Barros Montes. Rio de Janeiro: Contraponto/Editora PUC-Rio, 2006, p. 254.

4 Ibid., p. 256.

5 Ibid., p. 260.

${ }^{6}$ Ibid., p. 267.
} 
falar de um progresso moral do ser humano, isto é, de um senso maior de responsabilidade?

É inegável o progresso nas áreas científica e tecnológica de modo que a técnica atual é sempre mais perfeita que aquela que a antecedeu a tal ponto que a história de ambas é uma história de êxito. A técnica deixou de ser um meio para se tornar um fim em si mesmo já que a conquista da natureza se tornou a vocação da humanidade de modo que o homo sapiens se tornou instrumento do homo faber ${ }^{7}$. Jonas vê nessa atividade sem fim uma "utopia" que avança no caminho de uma "constante autossuperação a caminho de um objetivo infinito". O progresso da técnica é um progresso de resultados que podem ter tanto efeitos moralizadores como efeitos desmoralizantes, isto é, seus efeitos não vão necessariamente na direção de um avanço ético-utópico. Um regime despótico, por exemplo, alimenta crueldade, covardia, hipocrisia, traição e insensibilidade naqueles que exercem a tirania, premiando assim os piores aspectos da natureza humana e castigando os melhores. Ainda a exploração econômica tão criticada pelo marxismo tem efeitos perversos, do ponto de vista moral, tanto para os exploradores (insensibilização e consciência mentirosa) como para os explorados (perda da liberdade). A pobreza material conduz também à pobreza moral.

Jonas distingue dois tipos de utopia: aquela que se funda sobre o melhor estado possível (idealismo), sem se preocupar se tal projeto é realizável ou não, e aquela que se preocupa em fundar o melhor estado possível sobre as condições reais, não ignorando seus limites e condições (realismo). É nesse segundo caso que a utopia se mostra como o objeto real de uma esperança que vale a pena buscar por todos os meios possíveis. Mas há um terceiro tipo que é a do utopismo revolucionário. Assim, a utopia marxista se preocupa com as condições que vão levar a esse estado ideal e com as condições de realização de seu projeto. Ela se ocupa então do caminho que conduzirá ao homem verdadeiro.

Apesar das vantagens aparentes que o marxismo oferece quanto à possibilidade de uma política adequada à ética do futuro, Jonas vê nele também numerosos problemas ao examinar as condições reais de concretização da utopia marxista. A primeira objeção que ele levanta vem do fim buscado pelo marxismo que é a sociedade do lazer que liberaria o homem da fadiga de satisfazer suas necessidades; mas mesmo aí somente a técnica poderia proporcionar a abundância desejada de recursos e bens. Jonas se pergunta então pelo preço a ser pago pela natureza pelo fato de ela ter de suprir a todas essas exigências impostas pela sociedade do lazer. E se o ideal comunista deve ser universalizado,

\footnotetext{
7 Ibid., p. 272.
} 
como o marxismo propõe, isso só faz aumentar a possibilidade de uma catástrofe natural pelas seguintes razões: o aumento demográfico exige um aumento na produção de alimentos e de produtos consumíveis, devendo para isso intensificar a exploração dos recursos naturais. Já tendo se esgotado os recursos na superfície do solo terrestre, cada vez se faz mais necessário buscá-los nas profundezas dos oceanos além da necessidade que se impõe de novas formas de energia, como a nuclear, cuja utilização excessiva contribui enormemente para o aquecimento do planeta. A sociedade do lazer, almejada pelo marxismo, não seria possível sem esse aumento de produção de energia. Logo, a utopia marxista não respeita os limites estabelecidas pela própria natureza.

Uma outra objeção levantada por Jonas vem da ontologia do "ainda não" do ser que se encontra em Ernest Bloch. Em Marx, o ideal a ser atingido é o da liberdade em que não se trabalharia mais por necessidade, mas apenas voluntariamente por uma necessidade pessoal, de modo que os fins extrínsecos ao sujeito seriam eliminados, abrindo caminho para que a natureza humana se manifestasse em toda sua plenitude, isto é, o trabalho teria de deixar de ser um meio de sobrevivência para ser um trabalho livre, gratuito e desinteressado. A atividade substitutiva ao trabalho é, para Bloch, o lazer, pois nele o homem deixaria de estar submetido ao trabalho ${ }^{8}$. O lazer colocaria fim ao dualismo marxista entre trabalho manual e trabalho espiritual. Isso seria possível com a diminuição do trabalho humano proporcionada pela tecnicização crescente da produção. Mas Jonas não pensa que esse dualismo entre trabalho manual e trabalho espiritual possa ser eliminado com o esgotamento de um dos polos. O que aí desapareceria, a seu ver, é a oposição entre ação e inação, entre trabalho e não-trabalho, resultando num empobrecimento do trabalho que perde sua consistência, o que é incapaz de conduzir o homem a uma união feliz com o espírito 9 .

Se o trabalho perde sua consistência, faz-se necessário buscar fora dele uma compensação para o que nele é frustrante. Bloch, por sua vez, afirma que a felicidade utópica não se reduz a uma fruição passiva, mas que o lazer deverá ser um lazer ativo, de tal modo que o passatempo seja um passatempo pleno. Mas Jonas se pergunta se a espontaneidade, que deveria ser a marca constitutiva do lazer, não ficaria aí sacrificada além do fato de um lazer pleno ocasionar a perda de liberdade.

Jonas vê um risco em caso de o Estado concretizar a utopia marxista: o risco de o vazio deixado pelo trabalho não ser preenchido pelo lazer, abrindo assim espaço para a ociosidade com todas as suas possíveis

\footnotetext{
8 Ibid., p. 311ss.
}

9 Ibid., p. 317ss. 
consequências que, aliás, não diferem das consequências da desigualdade social, numa sociedade capitalista: crimes, violência, delinquência, etc. Em última instância, caberia ao Estado determinar quem pode exercer qual passatempo, quais cidadãos têm aptidão para exercê-lo, cabendo a ele impor a cada um sua atividade. Jonas pensa que isso faria com que a atividade humana perdesse toda sua realidade e consistência, mas, ao ver de Bloch, o homem ganharia em dignidade. Para Jonas, Bloch percebe essa perda de realidade da atividade humana, mas acha que ela é um mal menor comparado à perda de dignidade devido à necessidade do trabalho. Se para Marx, a liberdade se daria quando se atingisse o fim da necessidade de trabalhar, Jonas associa a liberdade à sua capacidade de se libertar constantemente do jugo da necessidade e, sem esse objeto, ela seria uma liberdade vazia que consequentemente deixaria de existir. Logo, a utopia marxista levaria à perda da liberdade ${ }^{10}$.

Ainda em sua leitura de Bloch, Jonas entende que ele quer dar ao lazer um outro conteúdo: o das relações intersubjetivas. Mas Jonas afirma que elas também são uma fonte de discórdia entre os homens. Embora a sociedade marxista acredite que ela pode extrair o melhor das relações intersubjetivas, evitando a discórdia, isso levaria o estado a se intrometer na vida privada dos cidadãos, ocasionando assim a perda de autonomia e de liberdade da parte dos cidadãos. As relações sociais, tal como são pensadas pela teoria marxista, fracassam em propor à sociedade o conteúdo sério que o estado de passatempo universal lhe fez perder. Para Jonas, as relações sociais precisam de algo que elas possam ter em comum, um mundo dentro do qual elas atuem ativamente, e a sociedade marxista as priva desse solo comum. Assim, a utopia de Bloch, além de negar realidade à ação humana, também o impede de se desenvolver em direção a uma intersubjetividade autêntica ${ }^{11}$.

Uma quarta objeção jonasiana a Bloch é que a sociedade marxista condiciona e é condicionada pela reconstrução da natureza, pois, ao mesmo tempo em que o homem humaniza a natureza pelo trabalho, essa natureza humanizada o livra da necessidade do trabalho da natureza, trazendo como consequência a humanização do homem. Para Jonas, tal humanização da natureza é o mesmo que submetê-la aos propósitos humanos, obrigando-a a nos fornecer tudo de que precisamos. Jonas vê Bloch se distanciando aqui de Marx, pois o homem alcançará a felicidade somente quando abandonar qualquer forma de relação estritamente utilitarista com a natureza. A natureza humanizada de Bloch não é a natureza submissa aos caprichos humanos, mas aquela que permite ao

\footnotetext{
${ }^{10}$ Ibid., p. 328ss.
}

${ }^{11}$ Ibid., p. 332. 
homem a plena realização de sua liberdade na sociedade do lazer. Mas mesmo assim, trata-se, para Jonas, de uma natureza reconstruída pelo homem, o mesmo projeto que nasceu com a técnica moderna, pois a natureza humana é a selvagem, aquela não tocada pelo homem, ao passo que a natureza submissa é a natureza inumana ${ }^{12}$.

Jonas conclui então que a utopia marxista não pode ser realizada nem seria de todo desejável, estando por isso condenada ao fracasso. Apesar de Bloch acreditar que a utopia permitiria ao homem uma reconciliação com o espírito, Jonas mostra que ela pode ocasionar um empobrecimento intelectual. Nem mesmo as relações intersubjetivas ganhariam em qualidade com o fim do trabalho. A natureza, por sua vez, também sofreria da alienação e da desnaturalização pelas quais os homens a fariam passar.

Um outro ponto ainda merece a atenção de Jonas: a ontologia do "ainda-não" do ser em Bloch segundo a qual nenhum ser atingiria a perfeição e a autenticidade antes do Estado marxista. Isso levaria o homem a uma busca incessante do radicalmente outro já que nem o passado nem o presente conheceram o homem no auge de sua perfeição e autenticidade, tarefa da qual o futuro deveria se incumbir. Bloch quer derivar o homem do futuro do ser do homem atual, mas suas formas tanto passadas como atuais sinalizam algo negativo que o homem futuro deverá negar em sua busca de autenticidade e perfeição. O passado deve então ser analisado para ver se se pode descobrir nele os indícios que apontam para o homem futuro. Assim, a história passada seria como que um preâmbulo à vida do ser humano autêntico, pois, para o utopismo radical, esse homem autêntico jamais existiu a não ser em sonho. Essa ideia é melhor traduzida pelo "ainda não" do ser em Bloch para quem cada ser conserva em si uma "tendência latente" a realizar-se plenamente.

O marxismo então concebe o homem a partir de uma potencialidade a ser desenvolvida, uma abertura em relação ao futuro como um leque de possibilidades que se abrem diante dele das quais o passado contém o germe. Passado e presente então só têm valor por conterem o germe do futuro. Jonas vê uma atitude paradoxal no marxismo a respeito do passado: ao mesmo tempo em que ele o culpa por não acolher em si mesmo o ser humano autêntico, ele o exalta por já conter em si o esboço do homem ainda por vir. Jonas critica essa filosofia marxista da história que vê uma época como antecipadora da seguinte, mas, a seu ver, cada época deve ser vista como um todo e não como a precursora da seguinte ${ }^{13}$.

\footnotetext{
${ }^{12}$ Ibid., p. 335ss.

${ }^{13}$ Ibid., p. 347.
} 
Assim Jonas critica o evolucionismo histórico em que a diversidade de culturas e de épocas é vista a partir de uma lógica do progresso.

Jonas rejeita essa ontologia marxista do "ainda não" do ser, afirmando que o homem autêntico sempre existiu apesar de todas as suas contradições. Essa ambivalência é própria do seu ser e é ela que o torna um ser autônomo e livre. A essência do homem não pode ser definida já que é próprio do homem se transcender em direção às possibilidades futuras que se abrem diante dele. Não há uma resposta pronta e definitiva aos apelos do futuro. A ideia utopista de uma natureza humana escondida, esperando as circunstâncias favoráveis ao seu desabrochamento, não faz sentido para Jonas. O passado não contém o futuro em germe, mas esse futuro será sempre imprevisível. Com isso, deve-se renunciar também ao ideal de uma perfeição humana total uma vez que o homem não é bom nem mau, mas traz em si a capacidade de ser tanto bom como mau ${ }^{14}$.

Ele pode se tornar tanto um santo quanto um monstro. Não há um estado ideal que, uma vez atingido, o satisfaça plenamente sem despertar o desejo de um outro estado, "toda satisfação pode gerar sua insatisfação". O homem conserva-se como fonte tanto do bem como do mal e essa capacidade é um valor, embora se deva aceitar o risco que ela traz consigo.

Jonas está convencido de que a crítica à utopia abre o caminho para a ética da responsabilidade que seria a única capaz de "segurar as rédeas desse progresso galopante" ${ }^{15}$. Só a responsabilidade pode nos livrar da fatalidade e de um certo determinismo histórico. Nosso destino final está sujeito à responsabilidade e não à necessidade. Podemos responder negativa ou positivamente a uma determinada perspectiva, incentivar ou impedir determinados desenvolvimentos. "Ao princípio esperança contrapomos o princípio responsabilidade, e não o princípio medo", diz Jona $\mathbf{s}^{16}$. O medo cumpre uma função pedagógica e é uma das "condições da ação responsável"; não deve ser um freio à ação, mas um estímulo que impõe um dever de agir quando um ser está em perigo devido à sua vulnerabilidade. É o objeto que nos interpela. Por isso, "a teoria da ética precisa tanto da representação do mal quanto da representação do bem..." de tal modo que assumamos a "responsabilidade pelo futuro do homem"17.

\footnotetext{
${ }^{14}$ Ibid., p. 345.

${ }^{15}$ Ibid., p. 349.

${ }^{16}$ Ibid., p. 351.

${ }^{17}$ Ibid., p. 353.
} 


\section{A Utopia em Levinas}

Passemos agora à maneira como Levinas aborda o tema da utopia que não é um tema que ocupa lugar de evidência em seu pensamento, mas aparece em alguns de seus textos, principalmente quando ele aborda autores mais conhecidos por suas reflexões sobre a utopia como Buber e Bloch.

No prefácio à obra de Buber, Utopie et Socialisme, Levinas a apresenta ressaltando os esforços de Buber em mostrar a parte involuntária ou inconsciente de todo utopismo, isto é, que o pensamento socialista é de ordem ética, profética e messiânica ${ }^{18}$. O utopismo ocupa o lugar da escatologia que teria perdido o sentido num mundo cada vez mais secularizado, após o Iluminismo e a Revolução Francesa, tornando-se então a maneira de buscar uma outra ordem social. No mesmo texto, Levinas louva os esforços de Bloch de regenerar o homem por inteiro, levando-o a se tornar aquilo que ele jamais foi em qualquer outra etapa da história. O "Princípio Esperança" de Bloch aponta para um outro futuro já prenunciado pelos profetas, filósofos e artistas.

Para Buber, a sociedade deve encontrar e aprofundar seus espaços a partir da oposição entre o político e o social, sem subordinar a sociedade civil ao Estado. O social, para Buber, diz respeito à vida comum dos homens, ao companheirismo, à presença de uns aos outros na proximidade que o socialismo deveria procurar regenerar ao recompor o tecido social abalado pelo político, pelo mercado e pela economia. Justifica-se então sua preferência por aquelas formas sociais que melhor atendem aos requisitos da cooperação, seja no trabalho, na produção ou na convivência. Tais formas descentralizadas que resistem à estatização são as que melhor representam o social e o "estar junto" dos homens. A produção deveria voltar ao controle dos trabalhadores. A sociedade sem classes, tão sonhada pelo marxismo, colocaria fim aos poderes políticos, devolvendo a administração da sociedade a ela mesma. As estruturas políticas seriam então provisórias até que se chegasse à sociedade nova. Mas Levinas já vê aí mesmo indícios da moral limitando a política, verificando a tendência do Estado em se afirmar com fim em si mesmo.

Nesse contexto, o socialismo aparece para Levinas como portando uma nova ética que se afirma objetivamente nos atos de resistência e até de martírio contra a perversão política, em nome de uma "utopia do humano". Para Levinas, é o modelo de relação Eu e Tu que permite pensar distintamente Sociedade e Estado e conceber uma coletividade

${ }^{18}$ LEVINAS, Emmanuel. Prefácio a BUBER, Martin. Socialisme et Utopie. Paris: Éditions Aubier Montaigne, 1977, p. 08. 
sem poderes centralizado ${ }^{19}$. Mas Levinas se pergunta se esse modelo do social que Buber propõe seria capaz de preservar a relação eu-tu, impedindo-a de cair no anonimato e na neutralidade de uma nova totalidade. Um pluralismo tal como Levinas o concebe deveria preservar a separação entre o eu e o tu, sem fundi-los numa unidade ou na homogeneização do Estado.

Embora também esteja interessado em priorizar a relação eu-tu e também situe a utopia no nível do encontro e da proximidade, Levinas não aceita caracterizar a relação eu-tu a partir da reciprocidade, pois é a altura do outro que o preserva em sua alteridade ${ }^{20}$. O outro só pode me questionar a partir de sua altura e da assimetria da relação intersubjetiva. A horizontalidade apagaria as diferenças entre o eu e o tu, sendo a verticalidade a única que é capaz de preservar tanto a altura como a diferença do outro. Não pode haver coincidência do eu e do si, sendo a reciprocidade um risco à integridade tanto do eu quanto do outro. É esse totalitarismo ontológico que resultaria num totalitarismo político ${ }^{21}$.

Levinas analisa ainda um texto de Bloch sobre a morte em que ele reconhece que o marxismo tira sua força tanto da reação moral contra os privilégios injustos e a miséria quanto da análise objetiva da realidade. Para ele, Bloch recupera os modos válidos da civilização humana (filosofia, arte e religião) que melhor representam a esperança humana de um outro futuro e de uma outra sociedade. "O marxismo desiste do céu para falar a linguagem da terra", diz Levinas ${ }^{22}$. Secularização aqui designa "a supressão de toda altura em que o homem não apareça". A ressalva de Levinas contra Bloch é que o humano é tratado por este a partir do ser e, ao mesmo tempo, "em sua irredutibilidade às coisas do mundo" ${ }^{23}$. A indignação ética de Bloch contra a miséria e a exploração econômica se une ao seu discurso lógico sobre o ser ou ao discurso ontológico, pois a "realização do homem é a realização do ser em sua verdade" 24.

Levinas vê aí já uma tensão entre o ontológico e o ético que ele melhor analisa a partir da resposta ao problema da morte. Na leitura que Levinas faz do marxismo de Bloch, a "inteligibilidade do ser coincidiria com o acabamento do inacabado", tendo papel decisivo nesse processo o trabalho e não a síntese kantiana do entendimento. $O$ trabalho aqui aparece como a condição transcendental da verdade que produz o ser juntamente com a matéria. A subjetividade do homem só se entende como

\footnotetext{
${ }^{19}$ Ibid., p. 08-11.

${ }^{20}$ LEVINAS, Emmanuel. Hors Sujet. Paris: Fata Morgana, 1987, p. 60-61.

${ }^{21}$ Idem. Difficile Liberté. Paris: Albin Michel, 1976, p. 289.

${ }^{22}$ Idem. De Dieu Qui vient à l'idée. Paris: Librairie Philosophique J. Vrin, 1998, p. 63.

${ }^{23}$ Ibid., p. 65.

${ }^{24}$ Ibid., p. 63.
} 
a de um trabalhador. A utopia tem de se realizar num dado momento da história já que a verdade do ser é a atualização da potência. Embora a práxis seja condicionadora da verdade, o seu futuro ainda não existiu em lugar nenhum, já que é "o futuro da utopia na abertura da pura experiência" 25 .

Levinas ressalta que na noção blochiana de temporalidade aparece algo em comum com a noção contemporânea de temporalidade, isto é, o futuro é o essencial da temporalidade. Mas, diferentemente de Heidegger, o nada da utopia blochiana "não é o nada da morte e o esperar não é angústia". Não é a morte que abre o futuro autêntico, mas a morte mesma deve ser compreendida em relação ao futuro da utopia uma vez que o futuro da utopia é a esperança de realizar aquilo que ainda não se realizou, isto é, aquilo que ainda não teve um lugar. Trata-se aí, na visão de Levinas, de uma subjetividade que não volta a si mesma, ao "cuidado de si da ipseidade", mas se abre ao mundo futuro da utopia. $\mathrm{Na}$ "obscuridade da facticidade" ou "na indeterminação em que se acha o sujeito", Bloch insere a esperança. Sua situação de fato não é a essência do homem, mas se encontram aí já os traços de um homem sem domicílio, embora Levinas veja aí ainda uma subjetividade estática, produzida pela práxis. O Bem, ao qual o sujeito se une no acabamento da utopia, não está além do ser e, ao alcançá-lo, abole-se a oposição entre homem e mundo. O medo da morte em Bloch não é angústia, mas o medo de deixar uma obra inacabada. Os momentos de obscuridade do sujeito são, no entanto, atravessados pela esperança da utopia, instantes estes que Bloch denomina "espanto".

O problema está, para Levinas, em que a salvação do homem ainda é pensada em termos de ontologia vista a partir de duas dimensões: a exclusão de toda referência à altura pelo fato de esta permanecer suspeita por se apresentar como sobrenatural e o fato de o ser se colocar no superlativo para aclarar a obscuridade do subjetivo. Levinas se pergunta se não há aí uma sugestão sobre a passagem do ser à condição de criatura. Também a elevação do ser ao superlativo não sugere a elaboração de uma dimensão de altura? Logo, a ontologia não estaria dando lugar à ética? Se há uma utopia em Levinas, esta só pode ser pensada em moldes éticos. A transcendência aí deve ter um lugar assegurado. Bloch ainda pensa a utopia no plano da imanência. Usando termos levinasianos, a utopia blochiana seria apenas uma necessidade que pode ser preenchida pela posse do objeto desejado enquanto o desejo levinasiano tem uma natureza metafísica. O desejo metafísico, como desejo do absolutamente outro, não aspira ao retorno a si, mas

${ }^{25}$ Ibid., p. 69. 
é um esforço constante de saída de si em direção ao outro. Se a utopia de Bloch se realiza com o alcance histórico do que ela almeja ou com a realização de uma essência inacabada, a utopia do humano, em Levinas, almeja o além do ser, o seu objeto é o outro transcendente, um não-lugar. A utopia seria a claridade onde o homem se mostra ${ }^{26}$.

Assim como Buber, a utopia levinasiana não se situa na história, mas num além da história. A utopia marxista se realizaria com o advento da sociedade sem classes e a propriedade coletiva dos meios de produção, mas essa satisfação, uma vez alcançada, não levaria a uma nova alienação? A ação da história, diz Levinas, precisa ser julgada a partir de um não-lugar de ordem escatológica já que a história não pode julgar a si mesma.

Em Le lieu et l'utopie, Levinas critica o individualismo ocidental em que o indivíduo solitário se vê como capaz de crescer sem limites, tudo suprimindo e monopolizando, sendo nada mais que um usurpador. A consciência deve se descobrir como solicitude pelos outros, ela é justiça. "Ser sem ser assassino": nisso consiste a ação ética. A ordem ética é o acesso mesmo à divindade ${ }^{27}$.

Levinas concorda com Buber que a relação é de uma originalidade tal que ela não conserva nada em comum com as categorias que aplicamos à relação com as coisas. O encontro eu-tu só é possível na proximidade, no face a face da relação ética, não sendo passível de tematização. $O$ rosto do outro cuja ordem é o "não matarás!" impõe a renúncia a todo desejo de apropriação de sua alteridade ou de eliminação de toda forma de exterioridade. É o outro que me elege e por isso o sujeito é refém. O humano não consiste na perseverança em seu próprio ser (conatus essendi) ou em expandir o próprio ser às expensas das necessidades negadas do outro que me interpela e a cujos apelos somente o eu pode responder em sua responsabilidade contraída num tempo imemorial anterior a toda autonomia. O humano, para Levinas, significa o começo de uma nova racionalidade, uma racionalidade ética, "racionalidade do bem mais alta que toda essência". É a "inteligibilidade da bondade"28.

Se a ética é a filosofia primeira, se a relação dual do face a face ético é a relação originária, porque ela parece tão ausente, deixando a relação social e política parecerem fundantes quando elas estão apenas fundadas na ética? Levinas aborda a questão a partir da ideologização da moral, mostrando que a força de mistificação da ideologia também a contaminou. O logos encobriu com sua força a ética que o precede, tornando-se, por

\footnotetext{
${ }^{26}$ LEVINAS, Emmanuel. Noms Propres. Paris: Fata Morgana, 1976, p. 52-53.

${ }^{27}$ Idem. Difficile Liberté. Paris: Albin Michel, 1976, p. 147.

${ }^{28}$ Idem. Entre-nous - Essais sur le Penser-à-l'autre. Paris: Grasset, 1991, p. 239-240.
} 
isso mesmo, a razão suspeita e omissa diante das injustiças. Portadora de uma força de ruptura, a ética denuncia a conivência da razão diante do sofrimento e da exploração do próprio homem pelo homem ${ }^{29}$.

A ciência, por sua vez, encobriu a vida com sua pretensão de verdade, substituindo o sujeito ético. Foi a ideologia que instalou um distanciamento entre o sujeito e a realidade, distanciamento que tornou possível a objetividade e a imparcialidade da ciência, ocasionando o abandono do valor como fator de sua inteligibilidade. O sujeito também passou a ser definido a partir da pulsão e do instinto, como se a razão fosse um tipo de razão prática. A axiologia foi então subordinada aos desejos, tendo a subjetividade humana desaparecido da teoria do conhecimento ${ }^{30}$.

O mundo contemporâneo, dominado pela tecnologia, fez o ser perder seus traços humanos e destruiu a transcendência. No entanto, o que se vê são os movimentos de ruptura que rejeitam o que está aí e buscam um outro mundo, ou seja, a ética interrompe o totalitarismo ontológico, denunciando o apagamento do outro e de suas demandas éticas, expondo-me como um refém de cuja responsabilidade pelo outro não posso escapar. Daí ser a ética uma ruptura da essência. Ela é o outro na proximidade, anterior ao conceito e fora de toda tematização, a transcendência antes da ciência e da ideologia ${ }^{31}$.

Concluindo, podemos dizer que a utopia levinasiana só pode ser pensada em termos éticos, isto é, ela é uma utopia do humano que é o "não-lugar" onde ela se assenta. Abensour mostra como o humano em Levinas tem uma ressonância utópica, tendo as marcas da imprevisibilidade e da indeterminação ${ }^{32}$. Só o humano é capaz então de desarranjar a ordem social já que comporta um excesso de sentido. Não possuindo um lugar que ela possa se realizar, a utopia se deixa orientar então por um desejo metafísico que a faz sempre buscar o humano na alteridade do outro. As duas figuras-chave da literatura ocidental, Abraão e Ulysses, indicam também dois movimentos: o daquele que parte sem conhecer o destino e sem jamais retornar ao ponto de partida (Abraão) e o daquele que representa a volta sobre si mesmo, o retorno à ilha natal (Ulysses). Na essência da utopia, tal como é pensada por Levinas, está esse movimento em direção ao outro homem, apontando para o além do ser e da perseverança no ser.

${ }^{29}$ LEVINAS, Emmanuel. De Dieu Qui vient à l'idée. Paris: Librairie Philosophique J. Vrin, 1998, p. 19.

${ }^{30}$ Ibid., p. 23.

${ }^{31}$ Ibid., p. 33.

${ }^{32}$ ABENSOUR, Miguel. Penser l'utopie autrement. In: Cahiers de l'Herne, n. 60, p. 482. 


\section{Considerações finais}

Jonas e Levinas se aproximam em sua leitura de Bloch, mas Jonas acusa a utopia blochiana de estar a serviço de um poder crescente do homem sobre a natureza como condição do surgimento de um homem superior. Ao não colocar entraves à ação cada vez mais abrangente do homem, estimulando ilimitadamente a ciência e a técnica, Jonas critica aquilo que Levinas também critica na ontologia: ela não consegue ter outro fim senão a expansão ilimitada do ser em seu esforço de perseverança.

A ética jonasiana não chega a romper com a ontologia, mas é construída sobre ela. Jonas rejeita a ideia de uma natureza humana fechada e definida, mas a vê como uma possibilidade aberta, podendo o homem se inclinar tanto ao bem quanto ao mal. O homem então não pode se instalar em nenhum estado, devendo sempre transcendê-lo. A responsabilidade se apresenta então como a arma que nos livra do determinismo histórico e nos abre a possibilidade de uma transcendência, embora ela ainda seja pensada em termos de uma ética fundada na ontologia.

A crítica de Levinas a Bloch se deve mais à incapacidade deste em romper com a ontologia, de pensar a utopia ainda em termos de imanência. A utopia levinasiana, ao ser pensada em termos éticos (utopia do humano), deve substituir aquela pensada ainda nos moldes da ontologia já que esta destrói a transcendência do outro. Vemos também aí a impossibilidade de o homem se "assentar" num determinado estado já que o desejo metafísico o leva à saída de si em direção ao outro, não alcançando jamais satisfação. O humano tem a característica da imprevisibilidade e não pode ser apagado seja pela ideologização da moral, seja pela ontologia que torna a razão indiferente ao sofrimento e às injustiças. Ele também acusa a ciência e a tecnologia de apagar os traços humanos do ser. Uma utopia do humano portador de um excesso de sentido cumpre a função de inquietar os arranjos socais e políticos que não atendem aos requisitos básicos da justiça devida a outrem.

\section{Referências}

ABENSOUR, Miguel. Penser l'utopie autrement. In : Cahiers de l'herne, $\mathrm{n}^{\circ} 60$.

JONAS, Hans. O Princípio Responsabilidade. Ensaio de uma ética para a civilização tecnológica. Trad. Marijane Lisboa; Luiz Barros Montes. Rio de Janeiro: Contraponto/ Editora PUC-Rio, 2006.

LEVINAS, Emmanuel. Entre-nous - Essais sur le Penser-à-l'autre. Paris: Grasset, 1991. . Éthique comme Philosophie Première. Paris: Éditions Payot \& Rivages, 1992. 
O. V. Carrara - Utopia em Jonas e Levinas

LEVINAS, Emmanuel. Éthique et Infini. Paris: Fayard, 1982.

. De Dieu Qui vient à l'idée. Paris: Librairie Philosophique J. Vrin, 1998.

. Difficile Liberté. Paris: Albin Michel, 1976.

. Hors Sujet. Paris: Fata Morgana, 1987.

. Noms Propres. Paris: Fata Morgana, 1976.

. Alterité et Transcendence. Paris: Fata Morgana, 1995.

SCHOEFS, Virginie. Hans Jonas: écologie et démocratie. Paris: L'Harmattan, 2009.

\section{Endereço postal:}

Universidade Federal Fluminense

Escola de Ciências Humanas e Sociais de Volta Redonda

Rua Desembargador Ellis Hermydio Figueira, 783 - Bloco A Aterrado

27213-415 Volta Redonda, RJ, Brasil

Data de recebimento: $12 / 10 / 2013$

Data de aceite: 13/04/2014 